\title{
Using platelet-to-lymphocyte ratio as a diagnostic marker in malignant ovarian tumors
}

\author{
Abdelfattah M. Agameya', Kareem Labib ${ }^{2}$, Fady Moiety ${ }^{1 *}$ \\ ${ }^{1}$ Department of Obstetrics and Gynecology, Medical College, Alexandria University, Egypt \\ ${ }^{2}$ Department of Obstetrics and Gynecology, Medical College, Ain Shams University, Egypt \\ Received: 17 March 2018 \\ Accepted: 30 April 2018 \\ *Correspondence: \\ Dr. Fady Moiety, \\ E-mail: fmoiety@gmail.com \\ Copyright: (c) the author(s), publisher and licensee Medip Academy. This is an open-access article distributed under \\ the terms of the Creative Commons Attribution Non-Commercial License, which permits unrestricted non-commercial \\ use, distribution, and reproduction in any medium, provided the original work is properly cited.
}

\begin{abstract}
Background: Ovarian malignancy, is the fifth global fatal disease for women, and the most common cause of death in Gynecological cancer. Objective was to evaluate any diagnostic role of Platelet-to-lymphocyte ratio in epithelial ovarian tumors.

Methods: A prospective analysis, over 1 year; (October 2016 to October 2017). Setting: University hospital's Gynaecological oncology centre. Subjects \& Methodology: A total of 36 patients with epithelial ovarian tumors, not under any adjuvant therapy and negative for any other malignancy, or any blood diseases causing blood count changes. All subjects underwent preoperative assessment of CA125 and Platelet-to-lymphocyte ratio (PLR), followed by a staging laparotomy and the appropriate management according to the standard protocols. Postoperative histopathological confirmation of the disease type, stage and grade was done for all cases.

Results: (77.8\%) of the patients had early stage disease while (22.2\%) had advanced stage. Neither mean platelet, lymphocytic counts, nor PLR express any significant difference between early and late stage disease. CA 125 levels, however changed significantly in advanced stages. PLR showed a statistically significant difference between the three stages of the disease $(\mathrm{P}=0.007)$. There was a positive correlation between PLR and CA125 ( $\mathrm{r}=0.184$ and $\mathrm{P}=0.283)$.

Conclusions: PLR rise significantly with tumor stages and correlates significantly with CA125. No significant change in PLR values with tumor type or grade. PLR might be a potential diagnostic / prognostic marker of ovarian epithelial cancer.
\end{abstract}

Keywords: Ovarian tumors, Platelet-to-lymphocyte, Ratio

\section{INTRODUCTION}

Ovarian malignancy is the fifth global fatal disease for Women, and the most common cause of death in Gynecological cancer. ${ }^{1}$ primary tumors of the ovary are most commonly (around ninety percent) derived from epithelial cells. ${ }^{2}$ Diagnosis of such a disease is mostly around the age 63 years. Epithelial ovarian cancer is more common in the United States with approximately 3-7 folds greater than Japan. ${ }^{3}$ Early detection/ screening could be the most acceptable way to decrease the disease's fatality, but recommendation of an ultimate screening test to the population at risk, seems difficult. Clinicians may find the non-specific, or the absence of symptoms of the disease a main obstacle for early detection. Biomarkers use for early diagnosis, needs an acceptable sensitivity without affecting the specificity. ${ }^{4}$ CA-125 was used for early detection of epithelial ovarian tumors, however, it is not specific for EOC, and tends to be affected by other coinciding diseases or malignancies. ${ }^{5}$ The most commonly used combination is that in which CA 125 and imaging methods are used together. 
However, this combination is not sufficient for early diagnosis due to the high cost of the imaging modalities and the CA125 low sensitivity. ${ }^{6}$

In epithelial ovarian malignancy, especially with poor prognosis, there would be elevation of neutrophils, platelets and relative decrease in lymphocytic count, increased platelet to lymphocyte ratio (PLR). ${ }^{7}$ This might be explained through an inflammatory process elicited by cancer cells, which would induce damage to cellular DNA, inhibit apoptosis and increase angiogenesis with a progressive tumor growth and metastasis.6,7 Some studies linked increased PLR with advanced stage diseases and limited survival. ${ }^{8}$

The platelet to lymphocyte ratio was defined as the platelet count divided by the absolute lymphocyte count. Ovarian cancers may be simply identified by preoperative PLR which is a cost-effective method as well. An elevated PLR may predict adverse outcomes in ovarian cancer. ${ }^{9}$ In this study, the diagnostic role of Platelet-to-lymphocyte ratio in epithelial ovarian tumors will be evaluated.

\section{METHODS}

This study represents a prospective analysis over duration of 1 year. The official ethical committee board's approval was granted before commencing the research. A total of 36 patients with epithelial ovarian cancer were recruited from Alexandria University-hospital's gynecological oncology center, during the period of October 2016 to October 2017.

All subjects were not under any adjuvant therapy and negative for any other malignancy, or any blood diseases causing blood count changes. All patients signed a full informed consent before commencement. Full history taking and thorough physical examination, imaging studies via transvaginal ultrasound (TVUS), and computed tomography were done for all subjects.

A preoperative serum sample was obtained using standardized sampling, separation and analyzing process for analysis of CA 125, PLR, and complete blood count was done. All enrolled subjects promptly received the appropriate management according to the standard protocols. Staging of the disease was also confirmed during surgery. Histopathology confirmed the disease in all subjects' ovarian specimens. The results were correlated with tumor type, stage and histological grade.

\section{Statistical analysis}

Data was analyzed using IBM SPSS software package version 20.0. (Armonk, NY: IBM Corp) using Student ttest to compare two groups for normally distributed quantitative variables, and pearson correlation coefficient, was used for the linear correlation between PLR and CA 125.

\section{RESULTS}

This study included 36 patients, the mean age of which age was 49.36 years (SD 10.805). 22 patients were menopausal $(61.1 \%)$.

Histology of tumor's in patients were serous in $41.7 \%$, Mucinous (16.7\%), Endometrioid (22.2\%), Clear cell $(3.9 \%)$, undifferentiated adenocarcinoma $(16.7 \%)$ and Brenner's tumor $(2.8 \%)$. $77.8 \%$ of the patients had early stage disease while (22.2\%) were at advanced stage. Laboratory tests are shown in Table 1.

Table 1: Laboratory tests.

\begin{tabular}{|ll|}
\hline Preoperative laboratory tests & Values \\
\hline Platelets $(\mathbf{X ~ 1 0} / \mathbf{c m m})$ & \\
\hline Min-Max & $174-700$ \\
\hline Mean \pm S.D. & $371.39 \pm 108.093$ \\
\hline Lymphocytes $(\mathbf{X ~ 1 0} / \mathbf{c m m})$ & \\
\hline Min-Max & $0.22-10.03$ \\
\hline Mean \pm S.D. & $2.447 \pm 1.683$ \\
\hline PLR & \\
\hline Min-Max & $1.468-401.9$ \\
\hline Mean \pm S.D. & $176.87 \pm 81.366$ \\
\hline CA125 (U/mML) & \\
\hline Min-Max & $4.11-2500$ \\
\hline Mean \pm S.D. & $307.1225 \pm 445.774$ \\
\hline
\end{tabular}

Neither mean platelet, lymphocytic counts, nor PLR express any statistically significant difference between early and late stage disease. CA 125 levels, however changed significantly in advanced stages (Table 2).

Table 2: Early VS. Advanced stage disease in terms of mean platelet and lymphocytic count $(X 103 / \mathrm{cmm})$, PLR, and CA $125(\mathrm{U} / \mathrm{mL})$.

\begin{tabular}{|c|c|c|c|}
\hline & $\begin{array}{l}\text { Early } \\
\text { stage }\end{array}$ & $\begin{array}{l}\text { Advanced } \\
\text { stage }\end{array}$ & $\begin{array}{l}\mathbf{P} \\
\text { value }\end{array}$ \\
\hline Platelets & $\begin{array}{l}372.68 \\
\pm 112.495\end{array}$ & $366.88 \pm 97.871$ & 0.896 \\
\hline Lymphocytes & $\begin{array}{l}2.619 \\
\pm 1.851\end{array}$ & $1.845 \pm 0.643$ & 0.257 \\
\hline PLR & $\begin{array}{l}165.940 \\
\pm 77.813\end{array}$ & $215.125 \pm 87.160$ & 0.134 \\
\hline CA125 & $\begin{array}{l}178.697 \\
\pm 147.942\end{array}$ & $\begin{array}{l}756.963 \\
\pm 782.183\end{array}$ & $0.001 *$ \\
\hline
\end{tabular}

Interestingly, PLR showed a statistically significant change of its mean value with advancing stage-to-stage tumor (Table 3).

PLR and CA125 showed a positive correlation $(r=0.184$ and $\mathrm{P}=0.283$ ) (Table 4, Figure 1). 
Table 3: Mean PLR at different stages of the disease.

\begin{tabular}{|llllll}
\hline PLR & Stage I & Stage II & Stage III & P value \\
\hline Mean \pm S.D. & $141.875 \pm 54.365$ & $214.367 \pm 53.951$ & $227.033 \pm 89.226$ & $0.007 *$
\end{tabular}

Table 4: Correlation between PLR and CA125.

\begin{tabular}{|c|c|c|}
\hline & & CA125 \\
\hline \multirow{2}{*}{ PLR } & $\mathrm{r}$ & 0.184 \\
\hline & $\mathrm{P}$ & 0.283 \\
\hline
\end{tabular}

\section{DISCUSSION}

Ovarian cancer has high case-to-fatality rates, where the fatal course of the disease is usually assumed to late diagnosis.1 Elevation of neutrophils, platelets, relative decrease in lymphocytic count, and increased platelet to lymphocyte ratio (PLR) are all findings in epithelial ovarian malignancy, indicative of poor prognosis. ${ }^{10}$ Detection of this cancer at an early stage, may promote the rates of survival of patients by up to $90 \% .^{11}$

Our finding confirmed that both PLR and CA 125 levels, changed significantly in advanced stages, and that PLR showed a statistically significant difference between the three stages of the disease as well as a positive correlation with CA125. X-M MA, et all concluded in their work that PLR rise means bad prognosis in ovarian cancer, which agrees with our findings in an indirect way. ${ }^{12}$ In concordance with our findings, Raungkaewmanee S. et al confirmed a potential clinical value for PLR in predicting advanced stage disease or suboptimal surgery. They also reported a better prognostic performance for PRL for survivals of EOC patients. They did not, however correlate with CA 125 levels. ${ }^{13}$ Asher V et al also reported PLR to be an independent marker for prognosis in patients with ovarian cancer. ${ }^{14}$ Prodromidou $\mathrm{A}$ et al also added that PLR seem to be a good screening and prognostic marker of cases with epithelial ovarian cancer. The cut-off values for accurate diagnosis remain undefined. They commented on the limited sensitivity and specificity, that might be limiting its use only as adjunct biomarkers for the detection of the disease. ${ }^{15}$ The Elevated pretreatment PLR, as referred to in our work , could be an unfavorable prognostic factor for clinical outcomes in patients with ovarian cancer, which was also concluded by Chuan T et al. ${ }^{16}$ Yildrim MA et al reported no significant difference between early and late stage disease regarding platelet count, lymphocytic count and PLR. ${ }^{17}$ The results of Kokcu A et al reported a significant elevation of both platelet counts, and PLR as well as a significant direct correlations with CA125, and a significant rise of PLR with advanced stage disease. ${ }^{18}$ This correlates well with present results.

These study limitations may include; the non-confirmed long-term follow up for prognosis, partly-nonhomogenous sample size, and not combining other markers for a more comprehensive to the diagnostic and prognostic performance.

\section{CONCLUSION}

PLR rise significantly with tumor stages and correlates positively and significantly with CA125. No significant change in PLR values with tumor type or grade. PLR might be a potential diagnostic / prognostic marker of ovarian epithelial cancer.

Funding: No funding sources

Conflict of interest: None declared

Ethical approval: The study was approved by the Institutional Ethics Committee

\section{REFERENCES}

1. Siegel R, Ward E, Brawley O, Jemal A. Cancer statistics. CA: a cancer. J Clinic. 2011 Jul 1;61(4):212-36.

2. Jemal A, Bray F, Center MM, Ferlay J, Ward E, Forman D. Global cancer statistics. CA: a cancer. J Clinic. 2011 Mar 1;61(2):69-90.

3. Daly M, Obrams GI. Epidemiology and risk assessment for ovarian cancer. Semin Oncol. 1998;25:255-64.

4. Van Haaften Day C, Shen YU, Xu F, Yu Y, Berchuck A, Havrilesky LJ et al. OVX1, macrophage-colony stimulating factor, and CA-125II as tumor markers for epithelial ovarian carcinoma. Cancer. 2001 Dec 1;92(11):2837-44.

5. Sinha P, Rastogi M, Agarwal V, Sachan M. Protein, Methylated DNA and Micro RNA: Potential Candidates Towards Sustainable Ovarian Cancer Diagnostics. Recent Adv Ovarian Cancer. 2016

6. Ashrafgangooei T, Rezaeezadeh M. Risk of malignancy index in preoperative evaluation of pelvic masses. Asian Pac J Cancer Prev. 2011 Jan $1 ; 12(07): 1727-30$.

7. Cho H, Hur HW, Kim SW. Pre-treatment neutrophil to lymphocyte ratio is elevated in epithelial ovarian cancer and predicts survival after treatment. Cancer Immunol Immunother. 2009;58:15-23.

8. Soonthorn Thum T, Suraseranee Wory V, Kengsakol $\mathrm{K}$, Wijaithmum K, Kasemsen $\mathrm{P}$, Prommatt S. Thrombocytosis in advanced epithelial ovarian cancer. J Med Assoc Thai. 2007;90:1495-500.

9. Dabrow MB, Francesco MR, Mc Breaty FX, Caradonna S. The effect of platelet derived growth factor and receptors on normal and neoplastic human ovarian surface epithelium. Gynecol Oncol. 1998;71:29-37. 
10. Gudducci A, Cosio S, Genazzani AR. Serum and tissue biomarkers as predictive and prognostic variables in epithelial cancer. Crit Rev Oncol Hematol. 2009;69:12-27.

11. Badgwell D, Bast Jr RC. Early detection of ovarian cancer. Disease Markers. 2007;23(5,6):397-410.

12. Ma XM, Sun X, Yang GW, Yu MW, Zhang GL, Yu $\mathrm{J}$ et al. The platelet-to-lymphocyte ratio as a predictor of patient outcomes in ovarian cancer: a meta-analysis. Climacteric. 2017 Sep;20(5):448-55.

13. Raungkaewmanee S, Tangjitgamol S, Manusirivithaya S, Srijaipracharoen S, Thavaramara T. Platelet to lymphocyte ratio as a prognostic factor for epithelial ovarian cancer. J Gynecol Oncol. 2012;23(4):265-73.

14. Asher V, Lee J, Innamaa A, Bali A. Preoperative platelet lymphocyte ratio as an independent prognostic marker in ovarian cancer. Clin Translational Oncol. $2011 \mathrm{Jul}$ 1;13(7):499.

15. Prodromidou A, Andreakos P, Kazakos C, Vlachos DE, Perrea D, Pergialiotis V. The diagnostic efficacy of platelet-to-lymphocyte ratio and neutrophil-to- lymphocyte ratio in ovarian cancer. Inflamm Res. 2017 Jun;66(6):467-75.

16. Chuan T, Wei S, Xia T, Yong S. Prognostic significance of platelet-to-lymphocyte ratio in patients with ovarian cancer: A meta-analysis. Eur J Clin Invest. 2018:e12917.

17. Yildirim MA, Seckin KD, Togrul C, Baser E, Karsli MF, Gungor T et al. Roles of neutrophil/lymphocyte and platelet/lymphocyte ratios in the early diagnosis of malignant ovarian masses. Asian Pac J Cancer Prev. 2014 Jan 1;15(16):6881-5.

18. Kokcu A, Kurtoglu E, Celik H, Tosun M, Malatyalıoglu E, Ozdemir AZ. May the platelet to lymphocyte ratio be a prognostic factor for epithelial ovarian cancer. Asian Pac J Cancer Prev. 2014 Jan $1 ; 15(22): 9781-4$.

Cite this article as: Agameya AM, Labib K, Moiety F. Using platelet-to-lymphocyte ratio as a diagnostic marker in malignant ovarian tumors. Int J Reprod Contracept Obstet Gynecol 2018;7:208992. 